\title{
Truly reconciled? A dyadic analysis of post-conflict social reintegration in northern Uganda
}

\author{
Matthew Osborne, School of International Development, University of East Anglia \\ (UEA) \& Behaviour and Choice Initiative, Stockholm Environment Institute (SEI)
}

Ben D'Exelle, School of International Development, University of East Anglia (UEA)

Arjan Verschoor, School of International Development, University of East Anglia (UEA)

\begin{abstract}
In the aftermath of civil war or violent internal conflict, one of the key peace-building challenges is the reconciliation of former enemies who are members of the same smallscale societies. A failure of social reintegration may contribute to what is known as a conflict trap. To detect lingering hostile attitudes among a community's various factions is crucial, but the approaches adopted in previous studies tend to focus on the impact of conflict on one or other aggregated indicator of social cohesion rather than on how violence-affected individuals regard and act towards their fellow community members. Here we demonstrate the value of concentrating on this latter dyadic component of social interactions and use behavioural experiments and a social tie survey to assess, in an appropriately disaggregated manner, social cohesion in a post-conflict setting in northern Uganda. Whereas in self-reported surveys, ex-combatants appear to be well-connected, active members of their communities, the experiments unveil the continued reluctance of other community members to share or cooperate with them; fewer resources are committed to ex-combatants than to others, which is statistically significant. The dyadic nature of our analysis allows us to detect which groups are more prone to discriminate against excombatants, which may help facilitate targeted interventions.
\end{abstract}

Keywords: post-conflict social reintegration, behavioural experiments, social tie survey, ex-combatants, northern Uganda

Corresponding author: matt.tom.osborne@gmail.com 


\section{Introduction}

Post-conflict social reintegration may hold the key to lasting peace. We know that internal civil conflicts have large, negative effects on prosperity (e.g. Rodrik, 1999; Murdoch \& Sandler, 2002; Murdoch \& Sandler, 2004; Chen, Loayza \& Reynal-Querol, 2008; Cerra \& Saxena, 2008). A failure of social reintegration may reinforce and entrench the effects of the resulting poverty, giving rise to a cyclical conflict trap, in which material hardship along with enduring hostile sentiments breeds future violence that perpetuates underdevelopment, and so on (Collier \& Hoeffler, 2004; Collier et al., 2006; DeRouen \& Bercovitch, 2008).

A key mechanism in the conflict trap stems from fractured societies. Conflicts have made enemies of people who should for the good of their communities live, work and trade peacefully together, but who may not be willing or psychologically able to do so, once arms have been laid down. Increasingly, post-conflict social reintegration is seen, both in the academic and in the policy literature, as an essential condition for lasting peace (UNDP, 2001; Collier et al., 2003; Paris, 2004; Doyle \& Sambanis, 2006; Spear, 2006; Del Castillo, 2008; Özerdem, 2012) and peace agreements that end internal conflicts now typically contain social reintegration programmes to prevent the disenfranchisement of excombatants and thereby reduce the likelihood of a future outbreak of conflict (Berdal \& Ucko, 2009; Knight, 2010).

The corresponding research challenge is to measure the extent to which social reintegration has taken place in the years following the end of conflict. One way of conceptualising social reintegration is to think of it as former enemies regarding and acting towards each other no differently than they do towards other community members. In this study, we quantify attitudes towards each other of community members engaged in a process of post-conflict reintegration. Our innovation is to match individuals on the roles they played in the recently ended conflict. We evaluate post-conflict social reintegration by concentrating on the social connections between pairs of individuals (dyads) who are purposively matched on conflict roles. For this purpose we designed a measurement instrument that we believe to be useful for assessing the extent to which post-conflict reintegration has taken place. 
We selected northern Uganda as the setting for this study. The specifics of the twenty years of civil war that started in the late 1980s meant that no self-selection into conflict roles took place: fighters were abducted by and indoctrinated into a rebel movement with virtually no popular support, and taught to terrorise the civilian population, including their own relatives and community members. As demonstrated for this civil war by Blattman \& Annan (2010), this absence of self-selection greatly reduces concern about potentially confounding factors: whereas factors such as ethnicity and religion are often correlated with conflict roles, this was not the case in the recently ended civil war in northern Uganda. As a result, the value of our instrument in detecting a lingering distaste for cooperating and sharing with former enemies can be more readily seen: other identity markers do not blur the picture. ${ }^{1}$

We used behavioural experiments in which subjects are matched on past conflict roles in a double-blind procedure so that neither they nor the experiment instructors know the reason for the pairing. Within matched pairs, we assess willingness to cooperate and willingness to share. Incentives are substantial: subjects would typically have to work several days to earn the money they leave the experiment with. For triangulation, a social tie survey is conducted immediately after the experiments that asks respondents to selfreport the nature of their relationship with the individuals they were paired with in the experiments. In order to complement the data on dyads, i.e. the experiments and social tie surveys, we administered a questionnaire to participants for collecting socio-economic, demographic and conflict history data. We also conducted key informant interviews to help us prepare for the fieldwork, as well as interpret our findings.

We find that about 15 percent fewer resources are committed to ex-combatants than to other community members, both in the sharing and in the cooperation experiments. This is in marked contrast to the findings from our social tie survey, in which ex-combatants appear to be as well-connected as everybody else. This suggests that behavioural experiments are good at capturing attitudes that people are reluctant to verbalise or in this case perhaps more plausibly hold unconsciously, because of an officially promoted norm of reconciliation: of forgiving and not discriminating against former enemies. Lab-in-the-

\footnotetext{
${ }^{1}$ At the same time, it is clear that the young were preferred to the old, and among the young, males to females by the rebel movement: we control for age and gender in the analysis.
} 
field experiments are increasingly used for research on discriminatory attitudes that, if expressed, may meet with psychological resistance or objections from others $;{ }^{2}$ our findings point to the field of post-conflict social reintegration as providing avenues for potentially fruitful extensions of such research.

The dyadic nature of our analysis also allows further probing of these results: we know which groups are particularly prone to discriminate against ex-combatants. We interpret the pattern of discrimination we find in terms of Tajfel \& Turner's $(1979,1986)$ social identity theory of intergroup behaviour and conflict. We argue that blame, resentment or conflict-related acquired personal characteristics are in context not plausible to explain the evidence for discrimination we find. Instead, we advance the explanation that conflict has created new social categories and therefore opportunities for categorical thinking: in-group favouritism and discrimination against the outgroup. Although their participation in the conflict was involuntary (they were forcibly abducted and forced to fight), ex-combatants have become an outgroup because of their conflict roles, which results in discrimination.

The article proceeds as follows. We first describe the literature related to our study, and briefly elaborate theoretical predictions for attitudes towards other categories of conflict participants in a post-conflict setting. Next we describe the research setting and methods for testing these predictions. This is followed by a presentation of our results, which are discussed in a concluding section.

\section{Related literature and theoretical framework}

\section{Contribution to the literature}

In this study, we contribute to two literatures. The first is studies that quantify social cohesion and reintegration in post-conflict settings. Previously, these have mainly relied on survey-based measures of trust in community members, of social and political activity, and of density of community-based associations. Generally speaking, aggregate proxy measures are used of social cohesion from various parts or periods of a conflict-affected area and the intertemporal or regional differences are taken as a measure of conflict's impact on such cohesion. Some find negative effects of conflict on interpersonal trust and

\footnotetext{
${ }^{2}$ A good illustration are recent experimental studies on the gendered intra-household allocation of resources such as Iversen et al. (2011), Jackson (2013), Kebede et al. (2014) and Munro et al. (2014).
} 
cooperation (Colletta \& Cullen, 2000; Thapa, 2003; Deng, 2010; Rohner et al., 2011; Cassar, Grosjean \& Whitt, 2013; De Luca \& Verpoorten, 2015), whereas others find positive effects of exposure to conflict on social cohesion, when that is proxied by participation in social activities, political engagement and community-level altruism (Bellows \& Miguel, 2006; Blattman, 2009; Voors et al., 2012).

The positive signs of social reintegration often found in these studies are good news but should also be met with some scepticism. Self-reported trust in community members may be subject to social desirability bias, which is especially pertinent when community leaders, NGOs and government are actively promoting peace; there is social pressure on people to conform to officially promoted norms. Social and political activity may be as much evidence of wishing to be accepted, or perhaps to make amends for past actions, as evidence of having been accepted. Associational density measures are aggregate proxies of what goes on between people, not based on direct observation of social connections; they may thus fail to detect lingering hostility present in some of these connections.

We side-step the limitations of the associational density and social and political activity measures by concentrating directly on the social interaction between individuals engaged in a process of reintegration. We attempt to overcome social desirability bias by using behavioural experiments that make it costly to conform with a norm of displaying no discrimination towards former enemies, when this is contrary to true preferences. ${ }^{3}$ The setup is thus designed to elicit behaviour that naturally comes without the interference of social desirability.

In addition to the literature that measures post-conflict social reintegration, we also contribute to experimental studies of social preferences in post-conflict settings. Echoing the surveys cited above, these have often found positive effects of conflict: on trust (Gilligan, Pasquale \& Samii, 2013; Cassar, Grosjean \& Whitt, 2013), trustworthiness (Becchetti, Conzo \& Romeo, 2013), altruism (Voors et al., 2012), cooperation (Gilligan,

\footnotetext{
${ }^{3}$ When asking sensitive questions in surveys, respondents may be reluctant to reveal socially undesirable attitudes, either to avoid embarrassment or because of incomplete cognitive processing (De Leeuw, 2005; Tourangeau \& Yan, 2007; Van de Mortel, 2008; Kaminska \& Foulsham, 2016). The latter, incomplete cognitive processing, would in our application correspond with unconsciously held attitudes towards former enemies. Experimental techniques have previously been used to help overcome social desirability bias (SDB) in surveys: to validate survey questions about which there are SDB concerns (Moshagen et al., 2013), and to reveal the discrepancy between evidence of socially undesirable behaviour based on responses to a survey and evidence of such behaviour obtained using an experiment (Fischbacher \& Föllmi-Heusi, 2013).
} 
Pasquale \& Samii, 2013) and the resilience of fairness norms (Whitt \& Wilson, 2007). At the same time, conflict experience has been linked to increased favouritism of the in-group ("parochialism") (Bauer et al., 2013), which however diminishes through frequent nonthreatening post-conflict interactions with members of other groups (Alexander \& Christia, 2011).

We add to these studies two innovations that we believe are crucial for quantifying postconflict social reintegration in a suitably disaggregated manner. The first is the purposive matching: by matching subjects from conflict-affected small-scale societies on conflict roles, which has not so far been done, we focus on the relationships that turned sour during the conflict, and the restoring of which forms the essence of post-conflict social reintegration. The second is the double-blind procedure, described below, which ensures that the effects on cooperation and sharing we find are not driven by experimenter demand effects: neither experimental subjects nor the assistants conducting the experiments are informed about anybody's conflict history, so that we rely on subjects' private knowledge about each other alone for obtaining treatment effects.

\section{Hypotheses}

For obtaining testable predictions, we reason from the insight that civil war has created new social categories: ex-combatants and civilians, of various types. These categories add aspects to people's social identity that did not exist prior to the conflict. In the case of northern Uganda, as we will see, these aspects are largely orthogonal to people's preconflict social identity: there is no correlation with ethnicity, religion or socio-economic status. After the conflict has ended, when people with various conflict roles form a community, these conflict-related aspects join other aspects of social identity, as well as personal characteristics, in informing attitudes towards other community members.

In the language of the influential social identity theory of intergroup behaviour and conflict developed by Tajfel \& Turner $(1979,1986)$, new in-groups and outgroups have been formed as a result of the conflict. The more salient the conflict-related aspects of social identity are, the greater the extent to which dealings with others will be influenced by their conflict roles as opposed to their other group memberships and personal characteristics. Because of these newly created groups or categories, there is thus a new 
potential for "categorical thinking": the tendency to attribute category characteristics to oneself and/or others. In social identity theory, to the extent that self-esteem correlates positively with group membership, the in-group will be more favourably treated than the outgroup in interpersonal relations: in-group favouritism. However, under certain conditions outgroup favouritism may occur, most significantly when members of a derogated group have internalised the esteem in which their group is held by other groups and believe boundaries between groups to be permeable (ibid.).

In the case of northern Uganda, again as will be seen, the derogated group is clear: those who were abducted by the rebel movement, forced to join their forces and returned to their original communities after the conflict ended. Although they are not explicitly blamed, they are the perpetrators of the devastating violence that paralysed northern Uganda for more than two decades; even if they are not held responsible for it, their presence in the communities represents the cause of the recent misery. Our first prediction is thus that other community members will display in-group favouritism and discriminate against the outgroup when it comes to their dealings with those abducted and who were forced to join the rebels.

Hypothesis 1: Abductees who were forced to join the rebels, are discriminated against by other community members.

In this particular context, the investigation of in-group favouritism and discrimination against the outgroup may be refined. A substantial proportion of northern Uganda's current population were also abducted by the rebels, but were then, within the next few days or at most a couple of weeks, released (some escaped). We postulate that those abducted but deselected would gain empathy from their own experience with those abducted and forced to be rebels. The process of othering, or in terms of social identity theory, the salience of the relevant outgroup characteristics will diminish accordingly. Our second prediction is thus that "short-term abductees" will show less in-group favouritism and discrimination of the outgroup in their dealings with "long-term abductees" than other community members will.

Hypothesis 2: Short-term abductees discriminate long-term abductees less than other community members do. 
For reasons alluded to above, whether or not the long-term abductees themselves will show in-group favouritism in their dealings with others is theoretically ambiguous. If they believe that boundaries between groups are not permeable, then a plausible strategy is to reject the low esteem in which they are held by others. In that case, we would expect them to show in-group favouritism. By contrast, if they believe that the conflict-related aspect of their social identity has become insignificant - stopped being salient in how they are regarded and regard themselves - then no in-group favouritism should be expected. Finally, if they believe that this aspect of their identity is still salient but may stop being so if they show goodwill to others, then outgroup favouritism is a possibility (cf. Tajfel \& Turner, 1979: 43-46).

\section{Setting and methods}

This study was located in northern Uganda where from the late 1980s, the Lord's Resistance Army (LRA) have plagued the majority Acholi population of the region. Operating from bases in southern Sudan, raiding parties would cross the border into northern Uganda, attack homesteads, usually at night, and take all residents, as well as the loot that could be carried. ${ }^{4}$ This indiscriminate short-term abduction, typically for no more than a couple of weeks at most, was followed by a selection process whereby some abductees would be retained by the LRA and others would be released (some escaped). Individuals retained would primarily be adolescents and young males who would become soldiers, but males and females of all but the most extreme age groups would also be retained to become porters, cleaners, cooks or "wives" (Annan \& Blattman, 2010).

Individuals who avoided LRA abduction were nonetheless significantly affected by the conflict, as from 1996 onwards the army started moving the rural population of northern Uganda into camps, in part as a counter-insurgency strategy ("draining the pond to catch the fish"), in part for their protection. At its peak in 2005, there were 1.84 million people or $\sim 90 \%$ of the rural population living in such Internally Displaced Persons (IDP) camps. Although no formal peace agreement was signed, the relocation of the LRA to the Democratic Republic of the Congo (DRC) from 2006 onwards improved the security situation and began to allow the camps' populations to return home. By 2010, the UNHCR

\footnotetext{
${ }^{4}$ For a fuller account of the LRA insurgency, see for instance Allen \& Vlassenroot (2010).
} 
had reported that virtually all of the IDPs and abductees who had not perished had returned to their villages of origin, now with a variety of conflict-affected pasts (IDMC, 2010; UNHCR, 2012).

Three distinct categories of conflict participation were thus created. The first category consists of those abducted by the LRA and then selected for membership, to be a soldier or to play another role it deemed useful. Once abductees were selected for membership, they would usually stay with the LRA for years. We call those long-term abductees (LTA).

The second category consists of those abducted by the LRA, but then de-selected. We will call these short-term abductees (STA). Their release would usually happen when the LRA reached a secure location where the sorting could take place undisturbed; often within a few days but always within a couple of weeks after the initial abduction. Since no LTA would stay with the LRA for less than a month, we imposed that as a cut-off point to distinguish between STA and LTA. The STA category is similar to the LTA category in one respect only: its initial traumatic abduction experience, which we hypothesise would lead to facilitate empathy with the LTA. In all other respects, they are similar to the next category: they would eventually, along with everybody else who were never abducted, be resettled by the army (Joireman, Sawyer \& Wilhoit, 2012).

The third category, the IDPs, experienced forced displacement, as well as the hardship of living in insecure and unsanitary camps, but were never abducted by the LRA.

The way in which the civil war created these three categories of people is outlined in Figure 1. Crucially, these categories have no basis in pre-conflict social identity. The uniform poverty of the area (i.e. no obvious wealth differences), the spatial arrangements of Acholi villages (i.e. households dwelling in the midst of their fields rather than in nucleated villages), the absence of rugged or other features of the terrain that make some parts easier to traverse than others, and the element of surprise and unpredictability that the LRA relied on for its success, meant that the likelihood of a household being attacked was not influenced by its characteristics. This is supported by studies that have examined households' pre-war traits and by interviews with former LRA officers (Blattman \& Annan, 2010). The indiscriminate nature of these LRA abductions has been characterised as a "tragic natural experiment" (Blattman, 2009: 231); the randomness of it has been used 
to identify the effect of violence on social, political and economic outcomes at the level of the individual abductee (Blattman, 2009; Blattman \& Annan, 2010).

For our purposes, the indiscriminate nature of LRA abduction means that the effect of conflict on post-conflict discrimination can be more clearly seen. Usual confounds such as ethnicity, religion or (pre-conflict) socio-economic status have played no role in the intergroup conflict in northern Uganda and are thus uncorrelated with new post-conflict aspects of social identity. At the same time, it is clear that the young were preferred to the old, and among the young, males to females, by the LRA: we control for age and gender in the analysis. In addition, selection on fitness for combat and health, possibly among other factors, will probably have taken place, for which we cannot control. Whereas such unobserved selection effects are in principle a concern for causal inference, their role is likely to be limited. The main advantage that the setting of northern Uganda offers for the purpose of this study is that conflict roles in its recently ended civil war had no basis in pre-conflict religious, ethnic or socio-economic identity.

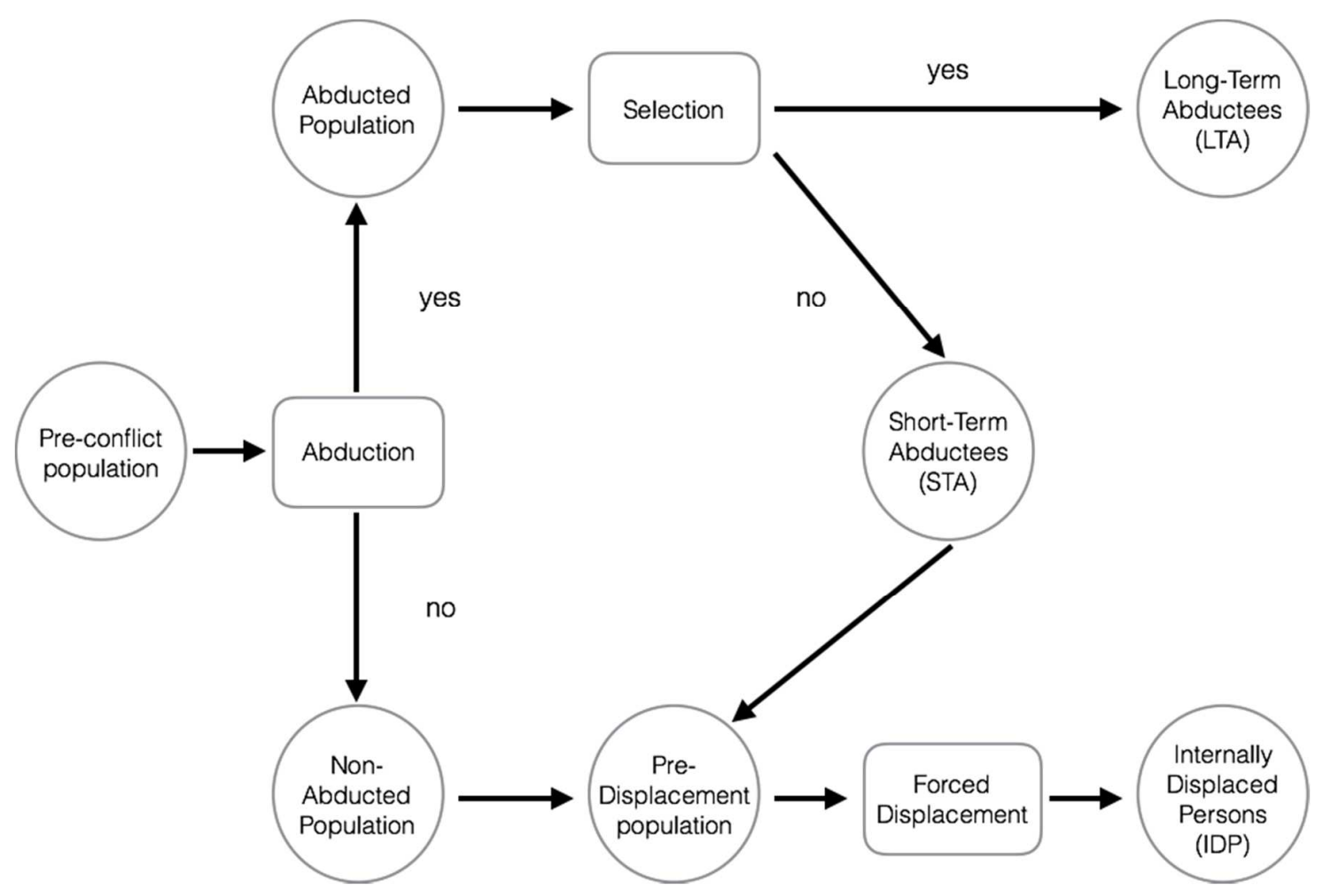

Figure 1. Assignment to conflict role 


\section{Data collection methods}

Data collection took place in 2012, between two and three years after the return of the displaced and abducted populations. Based on key informant interviews, we selected a subcounty, Mucwini, in the district of Kitgum, one of the three districts in which the LRA has been most active. The sub-county is sufficiently remote from Kitgum Trading Centre to encourage a tendency for village residents to primarily have relationships with each other - villages are socially integral. Mucwini has an estimated adult population of 9,831 divided over 79 villages in nine parish areas (UBoS, 2006) from which we selected, through implementing a multistage, stratified sampling design, 303 adults (18+) to be representative for the sub-county, as follows. For matching purposes, we ensured equal numbers in each of the three conflict categories described previously: Long Term Abductee (LTA), Short Term Abductee (STA) and IDP. The implementation of the sampling strategy is described in the online appendix.

In each of the nine parishes we organised one "game day", on consecutive days. All subjects played two games: a 'dictator' game and a 'cooperation' game, in each of which they were matched in successive rounds with a number of other players. After the games, subjects were invited to complete the social tie, socio-economic and conflict history surveys. The dictator game - whereby one player dictates the earnings of themselves and their nominated partner - has been widely used in behavioural economics since the early 1980s (Kahneman et al., 1986; Werner et al., 1982) and more recently in a number of postconflict scenarios (e.g. Whitt \& Wilson, 2007; Voors et al., 2012). The game is a one-stage game in which a participant (Player 1) decides how to divide an endowment between themselves and another participant (Player 2). If the dictator is not interested in the wellbeing of the other player, as well as remains anonymous, there is no reason why Player 1 should diminish their own earnings by offering anything at all to Player 2. However, a considerable body of research has shown that dictators generally transfer a non-trivial sum to their partner under a wide variety of experimental conditions (see the review in Camerer, 2003, and the meta study of Engel, 2011).

Dictator games originated as a means of observing the other-regarding preferences of individuals (altruism, etc.), although they have been increasingly used to measure 
perceptions of fairness as well as attitudes of discrimination (Berg et al., 1995; Fehr \& Schmidt, 1999; Cox, 2004; Frohlich, 2004). Since our interest is in a measure of goodwill towards other community members, we needed to ensure that the potential influence of reciprocity is minimised. We therefore imposed one-sided anonymity. In particular, we endowed Player 1, the dictator, with 10,000 shillings, 2.5 times the local daily wage, which they could divide as they wished between themselves and Player 2, whose identity was revealed to Player 1 but not vice versa.

The 'co-operation' game used in this study is adapted from well-known public goods games that have been in use for more than twenty years (Sugden, 1984; Ledyard, 1995). Essentially, public goods games capture a social dilemma: choose to act co-operatively at a personal cost or selfishly at a societal cost, i.e. 'defect' or free-ride on the efforts of others. Public goods games have been used in a variety of situations to explore the willingness of individuals to act collectively under a range of experimental conditions (Andreoni, 1995; Anderson et al., 1998; Brandts \& Schram, 2001; Levitt \& List, 2007). Here, we think of it primarily as measuring willingness to cooperate with community members variously implicated in a recently ended conflict.

To reduce confusion amongst participants, as well as avoid problems relating to reciprocity, the public goods game used in the study is limited to a simple interaction between two partnered individuals who must both choose how much of a given endowment they wish to keep for themselves and how much they would like to contribute to a collective 'investment'. Players 1 and 2 are told each other's identity and decide, without communication, how much of their individual endowment of 5,000 shillings to contribute to a common investment that earns $50 \%$ profit before being split equally between them. Clearly, if both players do not cooperate, each is worse off than if both had cooperated, but no matter what the other player does, each individual player is best off in monetary terms by not contributing anything.

Each subject played each game three times non-anonymously, each time matched with somebody from their own village with a different conflict history. This is the dyadic feature that, combined with matching on conflict role, distinguishes our study from previous ones. As is standard, only one decision is randomly selected for payment, after all decisions have been taken; subjects know this beforehand, so will consider each decision independently 
and knowing that it could be the selected one. All pairings, decision sequences and the ordering of the games were randomised too. As detailed in the online appendix, neither subjects nor experiment instructors were made aware of conflict roles or reasons for pairing: the names by which subjects had introduced themselves at the beginning of a session were used throughout. No explicit effort was thus made in the experimental sessions to render conflict roles salient, and any effect of being formerly in conflict on current sharing or cooperation in the matched pairs would derive from subjects' private knowledge of each other's history.

Following completion of the games, a survey was conducted which collected socioeconomic, attitudinal and social tie information about each participant; the information from the first two would be used as controls in the analysis of the games data, whereas the information on social ties provides the basis for complementary investigations.

Table I. Demographic and socio-economic characteristics and exposure to violence, by category

\begin{tabular}{|c|c|c|c|c|c|c|c|}
\hline & Total & IDP & STA & LTA & & Comparison & \\
\hline & $\mathrm{N}=275$ & $\mathrm{~N}=92$ & $\mathrm{~N}=92$ & $\mathrm{~N}=91$ & IDP - STA & IDP-LTA & STA-LTA \\
\hline Age & 36.90 & 39.22 & 39.26 & 32.46 & $\begin{array}{l}-0.05 \\
(2.51)\end{array}$ & $\begin{array}{l}6.76 * * \\
(2.16)\end{array}$ & $\begin{array}{l}6.80 * * \\
(2.10)\end{array}$ \\
\hline Male $(\%)$ & 53.26 & 48.91 & 44.57 & 65.93 & $4.35 \quad(7.35)$ & $\begin{array}{l}-17.02 * \\
(7.20)\end{array}$ & $\begin{array}{l}-21.37 * * \\
(7.18)\end{array}$ \\
\hline Education & 4.41 & 4.02 & 4.18 & 5.04 & $\begin{array}{l}-0.16 \\
(0.54)\end{array}$ & $\begin{array}{l}-1.02 \\
(0.56)\end{array}$ & $\begin{array}{l}-0.86 \\
(0.57)\end{array}$ \\
\hline Wealth & 0.00 & -0.04 & -0.14 & 0.18 & $\begin{array}{l}0.10 \\
(0.23)\end{array}$ & $\begin{array}{l}-0.22 \\
(0.24)\end{array}$ & $\begin{array}{l}-0.32 \\
(0.22)\end{array}$ \\
\hline $\begin{array}{l}\text { Attend community } \\
\text { meeting }(\%)\end{array}$ & 62.27 & 61.11 & 60.44 & 64.84 & $0.67 \quad(7.26)$ & $\begin{array}{l}-3.72 \\
(7.17)\end{array}$ & $\begin{array}{l}-4.40 \\
(7.16)\end{array}$ \\
\hline $\begin{array}{l}\text { \# of group } \\
\text { memberships }\end{array}$ & 2.99 & 2.91 & 2.87 & 3.22 & $\begin{array}{l}0.04 \\
(0.49)\end{array}$ & $\begin{array}{l}-0.31 \\
(0.51)\end{array}$ & $\begin{array}{l}-0.35 \\
(0.45)\end{array}$ \\
\hline $\begin{array}{l}\text { Threatened with } \\
\text { weapon }(\%)\end{array}$ & 62.91 & 48.35 & 56.52 & 83.52 & $\begin{array}{l}-8.17 \\
(7.36)\end{array}$ & $\begin{array}{l}-35.16^{* *} \\
(6.52)\end{array}$ & $\begin{array}{l}-26.99 * * \\
(6.47)\end{array}$ \\
\hline $\begin{array}{l}\text { Attacked with } \\
\text { weapon }(\%)\end{array}$ & 41.30 & 26.09 & 38.04 & 60.44 & $\begin{array}{l}-11.96 \\
(6.82)\end{array}$ & $\begin{array}{l}-34.35^{* *} \\
(6.87)\end{array}$ & $\begin{array}{l}-22.40 * * \\
(7.20)\end{array}$ \\
\hline Beaten $(\%)$ & 53.62 & 31.52 & 56.52 & 73.63 & $\begin{array}{l}-25.00^{* *} \\
(7.08)\end{array}$ & $\begin{array}{l}-42.10^{* *} \\
(6.69)\end{array}$ & $\begin{array}{l}-17.10^{*} \\
(6.93)\end{array}$ \\
\hline Lost body part (\%) & 6.88 & 6.52 & 3.26 & 9.89 & $3.26 \quad(3.17)$ & $\begin{array}{l}-3.37 \\
(4.05)\end{array}$ & $\begin{array}{l}-6.63^{*} \\
(3.64)\end{array}$ \\
\hline
\end{tabular}

a Independent samples t-tests and proportion tests were used for continuous variables and dichotomous variables, respectively. Mean differences and standard error (between brackets) reported. **, * indicate significance levels at 1 and 5 percent, respectively. 


\section{Results}

In this section we present the empirical results. ${ }^{5} \mathrm{We}$ will start with an analysis of the survey data, presenting descriptive statistics of important demographic and socio-economic characteristics as well as conflict exposure of the three different groups. In a next step, we will look at within-village social ties among the participants and whether there are any noticeable differences across (dyadic combinations of) the three groups. Finally, we investigate the experimental data to test the role of conflict history on pro-social behaviour. For this, we use a regression framework, which allows us to control for potential confounding factors, some of them identified by the descriptive analysis and the analysis of social ties.

\section{Individual characteristics of respondents}

We first examine the average demographic characteristics of the various groups within our sample (Table 1). As would be expected given the nature of the LRA abduction process, we find that LTA are on average younger and more likely to be male than STA (and IDP), which confirms that young males were more often wanted by the LRA, as suggested before. We do not observe any significant differences in education or wealth. ${ }^{6}$ In addition, and in line with other surveys in post-conflict settings (Bellows \& Miguel, 2009; Blattman, 2009), ex-combatants, here the LTA, are not less likely than others to be a member of communitylevel organisations or attend community meetings. Finally, we observe that LTA were more exposed to violence than STA, and STA in turn more than IDP. This supports that the assignment by the local village leaders into the different categories was done correctly.

\section{Social ties}

In a next step, we analyse social ties among the different categories, as captured by the social tie survey (STS) that was conducted after the experiments were completed. Table 2

\footnotetext{
${ }^{5}$ We did not deposit a pre-analysis plan in the public domain.

${ }^{6}$ To construct the wealth index we used a list of assets held by the individual as recorded in the survey. The index is formed by using the first principal component scores obtained with a principal components analysis. For a more technical exposition of this approach see Montgomery et al. (2000).
} 
presents the frequencies of social ties among the different categories. P1 refers to the respondent and P2 refers to the village member the social relation question is asked about. The percentages need to be interpreted as the percentage of dyads with $\mathrm{P} 2$ in which $\mathrm{P} 1$ reported a social tie. We focus on two types of social ties: friendship ties and ties that result from participating in the same social group. Our specific interest is in whether such ties are less frequent for the LTA than for others.

Looking at the friendship ties (panel a), we find that IDP tend to be somewhat less connected than LTA and STA, as indicated by the lower frequencies in the row with P1 = IDP and/or the column with P2 = IDP. The differences in frequencies, however, are not very substantial, and neither is the statistical significance of the differences. The most statistically significant difference is between P2 $=$ IDP and P2 $=$ LTA for the sample of all P1 (first row). On this evidence, LTA are if anything more likely than others to have friends within the community. Moreover, there is no evidence that members from other groups shun them in friendship relations.

Table II. Social ties within and across conflict categories

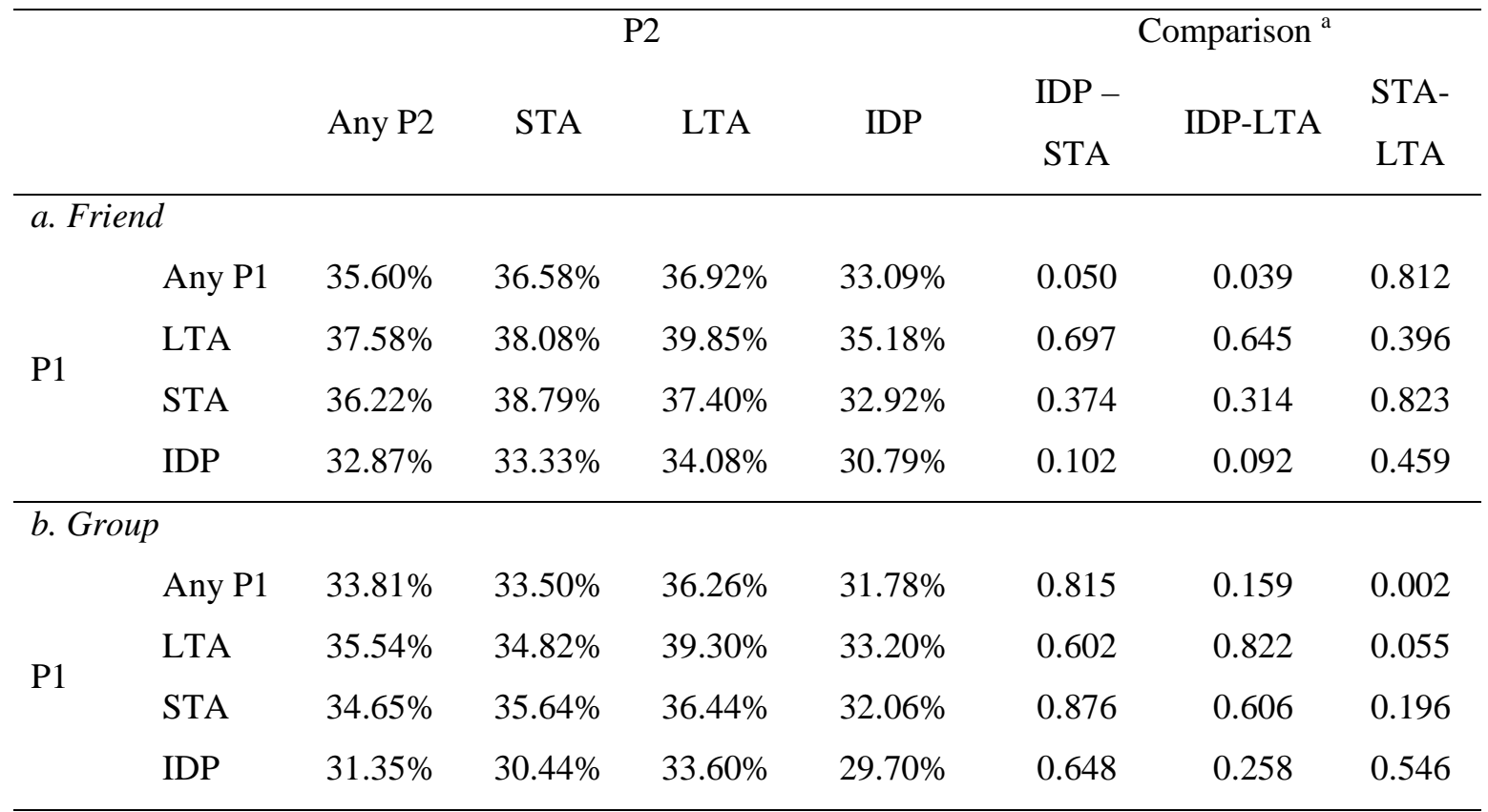

a Two-sided p-values of Wald test adjusted for multiple observations per P1. 
Looking at panel $b$, which presents the frequencies of connections via group membership, we again find that IDP are somewhat less connected than LTA and STA, as indicated by the lower frequencies in the row with P1 $=$ IDP and/or the column with $\mathrm{P} 2=$ IDP. We also observe that LTA tend to be more connected than STA. On this evidence, LTA are if anything more likely to belong to groups.

We thus conclude that in terms of both types of ties considered, the LTA are at least as connected as the other categories, both in the aggregate and with each of the other categories in the community.

Table III. Sharing and cooperation decisions by category of P2

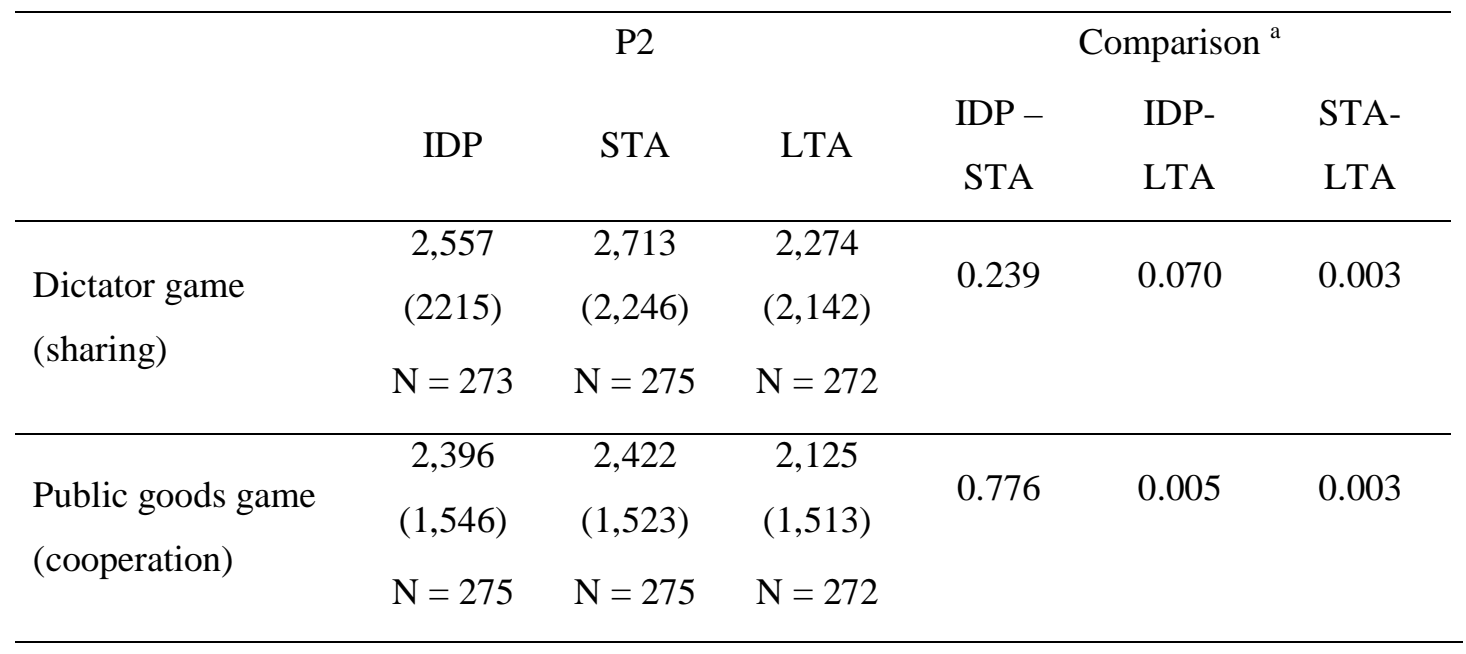

Mean decision made by person 1 by category of person 2 . Standard deviation between brackets. ${ }^{\text {a }}$ Paired samples t-tests for pairwise comparison of means. Two-sided p-values reported.

\section{Experimental data}

Finally, we look at the decisions made in the two experimental games. Table 3 presents the average amount shared in the dictator game and amount contributed in the public goods game, disaggregated by the category of P2. Here P1 refers to the decision maker and P2 to the paired person. On average about 25 percent of the initial endowment of 10,000 shillings was shared in the dictator game, and about 45 percent of the available 5,000 shillings contributed in the public goods game. Comparing the average amount shared or contributed across the different categories of $\mathrm{P} 2$, we find that the LTA receive 2,274 shillings on 
average in the dictator game, which is 16.2 percent less than what the STA on average receive, and 11.2 percent less than the IDP.

In the public goods game, players paired with an LTA contribute 2,125 shillings on average, or 12.3 percent less than what the STA on average experience and 11.3 percent less than the IDP. In the pairwise comparison LTA versus STA, the difference in sharing experienced of 439 shillings is statistically significant as well as the difference in cooperation experienced of 297 shillings; in the pairwise comparison LTA versus IDP, the same is the case for cooperation (contribution is a statistically significant 271 shillings lower when matched with LTA) although not for sharing.

To test our two hypotheses, we estimate the following regression model:

$$
y_{i j}=\beta_{0}+\beta_{1}(\mathrm{P} 2=\mathrm{LTA})+\beta_{2}(\mathrm{P} 2=\mathrm{IDP})+\beta_{3} X_{i}+\sigma_{i}+\varepsilon_{i j}
$$

We include two dummy variables in the regressions that control for two of the three categories of the matched person $(\mathrm{P} 2)$, using the STA category as reference category, hence omitted. The coefficient on LTA is the central coefficient of interest, which should thus be interpreted as the extra sharing/cooperation experienced by the abductees who became LRA members compared to the abductees who shortly after their abduction were released, so never joined the LRA. Recall that hypothesis 1 states that LTA are discriminated against by other community members. This would be confirmed in the empirical analysis if in the $\mathrm{P} 1=\mathrm{STA}$ and/or P1=IDP regressions, the coefficient on LTA is negative and statistically significant. Stated more fully, if in either of these two separate regressions for the other community members as Player 1 (a regression for the STA and a regression for the IDP) the coefficient on LTA is negative, then this points to discrimination by the category of other community members whose Player 1 behaviour is studied in that regresssion. Hypothesis 2 offers a refinement and states that STA discriminate against LTA less than the IDP do. We evaluate this hypothesis by comparing the coefficient on LTA across the $\mathrm{P} 1=\mathrm{STA}$ and $\mathrm{P} 1=\mathrm{IDP}$ regressions.

To limit omitted variable bias, we include a vector of control variables, represented by the vector $X_{i}$. More specifically, we control for gender, age, education and wealth of the matched person P2. To control for all (observed and unobserved) characteristics of person $\mathrm{P} 1$, we include individual fixed effects, represented by the term $\sigma_{i}$ (making use of the 
within-subject experimental design). Given the potential influence of social ties on prosocial behavior (on this see e.g. Leider et al., 2009; Ligon \& Schechter, 2012) and its correlation with conflict categories (see Table 2), we also control for the existence of a social tie between P1 and P2 (as reported by P1). Finally, $\varepsilon_{i j}$ captures any remaining idiosyncratic error. We applied robust standard errors clustered at the village level so as to conservatively account for possible non-independencies within villages and experimental sessions (we conducted only one session per village).

Table 4 presents the estimates of the regressions for the public goods (models 1-4) and the dictator game (models 5-8); as mentioned, the public goods game measures cooperation behaviour, the dictator game sharing behaviour. We use the pooled sample (models 1 and 5) and different subsamples for each category of P1, which allows us to identify differences across types of dyads (i.e. P1 and P2 combinations), needed to test our predictions.

Table IV. Sharing and cooperation within and across conflict categories

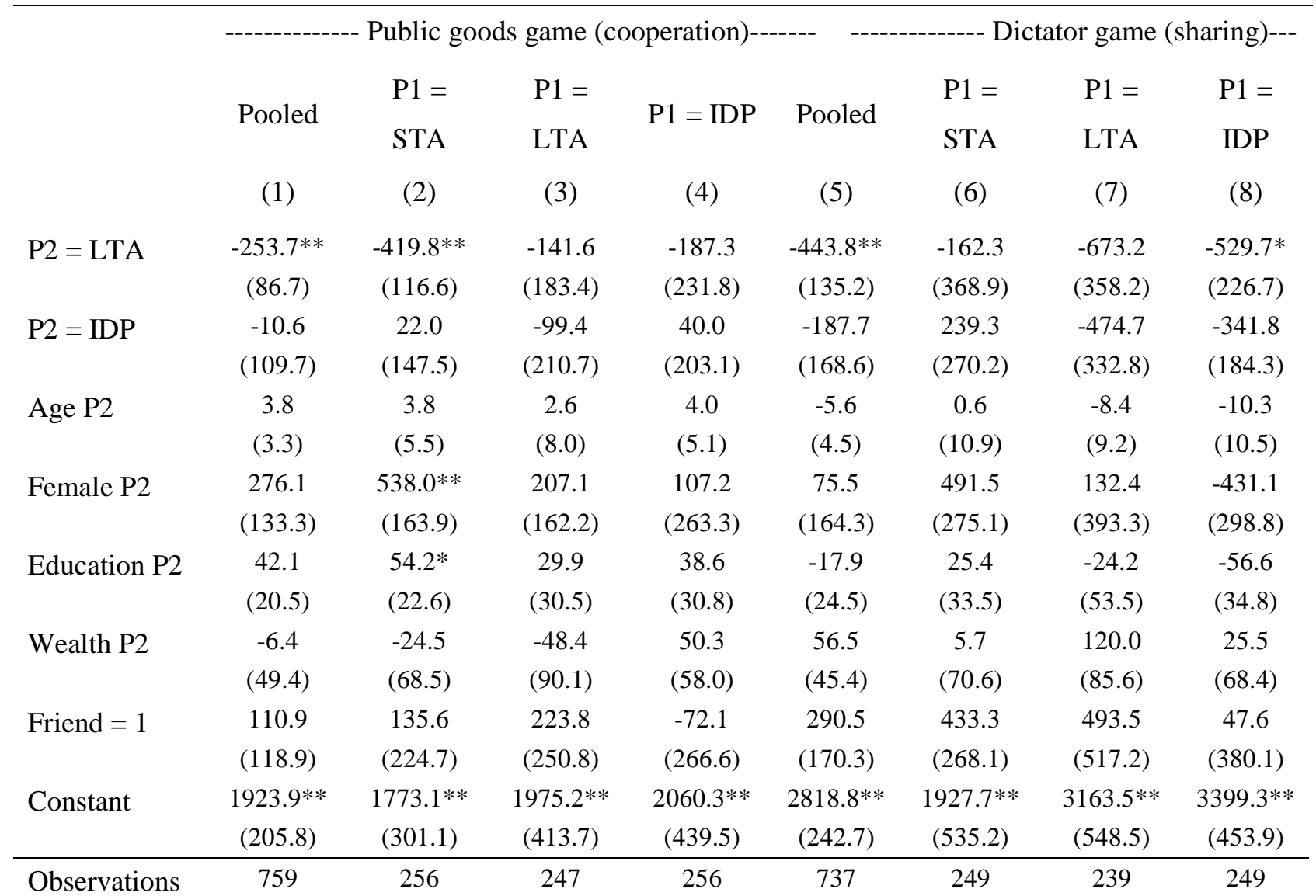




\begin{tabular}{lllllllll} 
R-squared & 0.045 & 0.144 & 0.025 & 0.029 & 0.026 & 0.050 & 0.051 & 0.049 \\
F & 3.079 & 8.664 & 0.434 & 0.885 & 2.162 & 1.118 & 1.312 & 1.837 \\
\hline
\end{tabular}

Fixed effects regressions with controls for age, gender, education and wealth of person 2. P2 = STA used as reference category. Standard errors clustered at village level in parentheses. **, * indicate significance levels at 1 and 5 percent, respectively.

Looking at the results of the pooled sample we find similar results for both games. In the public goods game (model 1) the coefficient of 'P2 = LTA' is statistically significant, and its sign and size indicate that P1 contributes on average 253.7 less when P2 is an LTA than when P2 is an STA. The coefficient of 'P2 = IDP' is not statistically significant, which indicates that P1 tends to contribute similarly when matched with IDP as when matched with STA. In the dictator game (model 5) again the estimated coefficient of 'P2 $=$ LTA' is statistically significant. Participants tend to share 443.8 less when matched with an LTA than when matched with an STA. The coefficient of 'P2 = IDP' is not statistically significant, which indicates that P1 tends to share similarly with IDP as with STA.

Because of the dyadic element of our games, we are able to examine who is generous/cooperative towards whom. ${ }^{7}$ For this, we look at the estimates of the subsamples which allow us to identify which category of P1 drives the observed lower sharing and cooperation with LTA. For the public goods game, we find that all three categories tend to contribute less when matched with LTA than with STA. The negative coefficient on LTA in the $\mathrm{P} 1=\mathrm{STA}$ and the $\mathrm{P} 1=\mathrm{IDP}$ regressions are consistent with hypothesis 1 , according to which other community members discriminate against LTA. However, only for decision makers who are STA (model 2) is the coefficient of 'P2 = LTA' statistically significant. This indicates that the lower contributions with LTA are driven by STA, a rejection of hypothesis 2 , which expects a greater willingness to cooperate with the LTA among the STA than among the IDP. In shillings, STA tend to contribute 419.9 less when matched with LTA, compared to when matched with STA. ${ }^{8}$ The coefficient of 'P2 $=$ IDP' is not statistically significant in any of the subsamples, which indicates that all categories contribute similarly when matched with IDP as with STA.

\footnotetext{
${ }^{7}$ This involves multiple comparisons, and therefore a possible inflation of a type 1 error. Rather than using Bonferroni corrections - which tend to be too conservative - we focus instead on the most statistically significant results.

${ }^{8}$ The next mentioned finding rules out that this is an in-group effect: STA do not favour themselves over IDP, only over LTA.
} 
For the dictator game, we find that all three categories tend to share less with LTA than with STA, but that only for decision makers who are IDP (model 8) the difference is statistically significant. More specifically, IDP share on average 529.7 shillings less with LTA than with STA. We thus find support for both hypotheses 1 and 2 in the dictator game: other community members share less with the LTA than with others (hypothesis 1), but this lack of sharing is attenuated when the dictator is an STA (hypothesis 2). The coefficient of 'P2 = IDP' is not statistically significant in any of the subsamples, which indicates that all categories treat IDP similarly to STA.

A succinct way of summarising the results from both games is to say that STA discriminate against LTA in cooperation (and only against LTA), whereas IDP discriminate against LTA in sharing (and only against LTA).

What do these results tell us about the predictions from social identity theory arrived at above? For both sharing and cooperation, we find support for our first prediction (hypothesis 1): LTA are discriminated against. They receive less in the dictator game than others do, which is driven by the sharing behaviour of the IDP; and less money is committed to cooperation with the LTA, which is driven by the behaviour of the STA. Our second prediction (hypothesis 2), according to which STA discriminate less against LTA than the IDP do, is supported when it comes to sharing behaviour: lower sharing with the LTA in the dictator games is driven by the behaviour of the IDP. However, our second prediction is contradicted in the public goods games: STA discriminate more against LTA in cooperation than the IDP do. For LTA behaviour, social identity theory does not imply a clear-cut prediction, as explained above; both in-group and outgroup favouritism are possible, depending among other factors on the extent to which the derogated group identifies with the low esteem in which it is held by others. The negative sign of the coefficients on 'P2 $=$ LTA' in the two 'P1 $=$ LTA' models (models 3 and 7) are consistent with outgroup favouritism; but they are not statistically significant. At any rate, there is no evidence of in-group favouritism among the LTA, nor of discrimination by them against either of the other two categories. We will next reflect on these patterns of discrimination.

\section{Discussion and conclusion}


A civil war creates new social categories, new aspects of social identity. When arms have been laid down, these conflict-related aspects of social identity remain. To the extent that they remain salient, social identity theory of intergroup behaviour predicts discrimination against those whose conflict roles place them in the derogated social category: the longterm abductees in northern Uganda.

We find in a survey that long-term abductees are at least as often active members of community organisations, and at least as often reported to be friends. Social ties exist abundantly among them and exist as frequently as they do for others with those outside their own group. However, in behavioural experiments, other community members are less likely to be cooperative or generous towards them: averaged across all community members, about 15 percent fewer resources are committed to long-term abductees in each of these acts, which is statistically significant (Table 4, columns 1 and 5). A lingering distaste for cooperating and sharing with former enemies is thus detected that was not detected through a survey.

In the context of the recently ended civil war in northern Uganda, a newly acquired postconflict social identity is the most plausible factor responsible for the discrimination of excombatants. Our reasons for concluding this are (a) that the post-conflict social identity of the former rebels has no basis in pre-conflict social identity, which follows from the nature of the LRA abduction process, as argued above; and (b) that previous research does not support for this setting any of the other major explanations for discrimination reported for other settings in studies of post-conflict social reintegration, as we will argue next.

The literature on post-conflict social reintegration suggests three major explanations for discrimination of ex-combatants: they are blamed, they have changed or they are resented. As to the first explanation, ex-combatants are often found to be stereotyped or otherwise negatively labelled because of their violent past (e.g. Muggah, 2005). However, former LRA members were welcomed back first by their families and next by the wider communities, with very high rates of acceptance reported (Annan et al., 2007). A key factor appears to have been widespread recognition that they were not abducted by choice and therefore not to blame for their violent behaviour.

The second explanation, by which ex-combatants have become different persons because of their implication in violence that affects their interaction with others, is 
controversial in northern Uganda, with studies reaching different conclusions about the extent to which ex-LRA members have been negatively affected in their capacity to function as effective community members (Pham \& Vinck, 2010). The study of Blattman \& Annan (2010) and the studies cited therein point to remarkable trauma-induced psychological growth and conclude that post-traumatic stress disorder was found among a comparatively small group of former abductees and not disproportionately frequently in this group, whereas Derluyn et al. (2004) report for this group almost universal posttraumatic stress symptoms of clinical importance. ${ }^{9}$ But whatever the true psychological damage may be of their conflict history, ex-LRA members are more than others active in their community (Blattman, 2009), so it would be difficult to uphold an account of their discrimination that rests on them being "anti-social".

A third possible interpretation of our findings, that ex-combatants are resented for the official help they receive, which is often found elsewhere (Blattman, 2010) is implausible in northern Uganda: material support was sparse for ex-combatants and IDPs alike. ${ }^{10}$

Since blame, changed characters or resentment do not provide a convincing rationale for discrimination, it is thus plausible that the discrimination we found evidence for is a "pure" bias against the outgroup. The evidence thereby provides support for a key prediction of social identity theory of intergroup behaviour and conflict: the social category "ex-combatant", irrespective of other motives for discrimination, labels a derogated group that is likely to suffer from discrimination. The new derogated group created by the conflict consists in this context of ex-LRA members, or long-term abductees. The discrimination resulting from the new label is clear to see since there are no obvious other motives for discrimination, nor does the label correspond with a pre-conflict social identity.

How should the particular pattern of discrimination we found be interpreted? The dictator game measures how kindly disposed towards ex-combatants other people are. Those who were themselves briefly abducted do not discriminate against the long-term abductees in the dictator games; those who were never abducted do. This suggests both that the long-term abductees are regarded as an outgroup and that sharing the abduction

\footnotetext{
${ }^{9}$ See also Pham, Vinck \& Stover (2009) for evidence that forced abduction is a significant factor in how the LRA-led conflict has affected the psychological well-being of northern Ugandans.

${ }^{10}$ Source: Interviews with village representatives from each of the participating villages in August 2012.
} 
experience gave rise to empathy that reduces the salience of the outgroup characteristic "long-term abductee".

On the other hand, discrimination in the public goods game reflects a character assessment of the person one is paired with: how likely is it that they will cooperate? We found that short-term abductees discriminate against long-term abductees in the public goods games. This suggests that they are unaware of the actual willingness to cooperate of the long-term abductees. This is supported by the findings of Bauer et al. (2015), who report similar ignorance of the trustworthiness of ex-LRA members. The exception to this general pattern they report is for those who know the ex-LRA members well (as their sons). The absence of discrimination of the ex-LRA members in the public goods games that we found by those who were never themselves abducted thus suggests that the latter assess correctly that the former are cooperative.

Ex-LRA members themselves do not display in the experiments statistically significant in-group nor outgroup favouritism. In terms of social identity theory of intergroup behaviour and conflict, this suggests that they believe that the conflict-related aspects of their social identity have become insignificant (in marked contrast to what other community members believe about them). The widely promoted and apparently embraced reconciliation thus appears to have been taken, by former rebels, at face value; the discrimination against them that we found evidence of in the experiments may be an unacknowledged undercurrent: unconsciously held attitudes towards the former rebels by other community members.

To conclude, our analysis shows the value of combining behavioural experiments and a social tie survey for studying post-conflict social reintegration. Whereas the social tie survey shows the reported connections between former enemies (as friends, as members of the same social group), behavioural experiments detect possibly unconsciously held attitudes towards former enemies. Knowing whether connections such as friendship and group membership are reported to exist is not enough: there may be lingering animosity under the surface, which experiments can uncover.

\section{Data replication}


The dataset, codebook, and do-files for the empirical analysis in this article can be found at http://www.prio.org/jpr/datasets.

\section{Acknowledgements}

Please insert here if any.

\section{References}

Alexander, Marcus \& Fotini Christia (2011) Context modularity of human altruism. Science 334(6061): 1392-1394.

Allen, Tim \& Koen Vlassenroot (2010) The Lord's Resistance Army: Myth and Reality. London: Zed. Anderson, Simon P; Jacob K Goeree \& Charles A Holt (1998) A theoretical analysis of altruism and decision error in public goods games. Journal of Public Economics 70(2): 297-323.

Andreoni, James (1995) Cooperation in public-goods experiments: kindness or confusion? American Economic Review 85(4): 891-904.

Annan, Jeannie \& Christopher Blattman (2010) On the nature and causes of LRA abduction: What the abductees say. In: Tim Allen \& Koen Vlassenroot (eds) The Lord's Resistance Army: Myth and Reality. London: Zed, 132-155.

Annan, Jeannie; Christopher Blattman \& Roger Horton (2007) SWAY I: State of Youth and Youth Protection in Northern Uganda: Findings from the Survey of War Affected Youth. UNICEF.

Annan, Jeannie; Christopher Blattman, Dyan Mazurana \& Khristopher Carlson (2011) Civil war, reintegration and gender in northern Uganda. Journal of Conflict Resolution 55(6): 877-908.

Bauer, Michal; Alessandra Cassar, Julie Chytilova \& Joseph Henrich (2013) War's Enduring Effects on the Development of Egalitarian Motivations and Ingroup Biases. Psychological Science 25(X): 47-57.

Bauer, Michal; Nathan Fiala \& Ian Levely (2015) Trusting former rebels: An experimental approach to understanding reintegration after civil war. Charles University Center for Economic Research and Graduate Education Academy of Sciences of the Czech Republic Economics Institute, CERGE EI Working Paper Series 512: 1 (http://ies.fsv.cuni.cz/default/file/download/id/27155).

Becchetti, Leonardo; Pierluigi Conzo \& Alessandro Romeo (2013) Violence, trust, and trustworthiness: evidence from a Nairobi slum. Oxford Economic Papers 2013: 1-23.

Bellows, John \& Edward Miguel (2006) War and Institutions: New Evidence from Sierra Leone. The American Economic Review 96(2): 394-399.

Bellows, John \& Edward Miguel (2009) War and local collective action in Sierra Leone. Journal of Public Economics 93(11-12): 1144-1157.

Berdal, Mats \& David H Ucko (2009) Reintegrating Armed Groups after Conflict: Politics, Violence and Transition. Abingdon: Routledge.

Berg, Joyce; John Dickhaut \& Kevin McCabe (1995) Trust, reciprocity and social history. Games and Economic Behaviour 10(1): 122-142.

Blattman, Christopher (2009) From violence to voting: War and political participation in Uganda. American Political Science Review 103(2): 231-247 
Blattman, Christopher \& Jeannie Annan (2010) The consequences of child soldiering. The Review of Economics and Statistics 92(4): 882-898.

Brandts, Jordi \& Arthur Schram (2001) Cooperation and noise in public goods experiments: Applying the contribution function approach. Journal of Public Economics 79(2): 399-427.

Cassar, Alessandra; Pauline Grosjean \& Sam Whitt (2013) Legacies of violence: Trust and market development. Journal of Economic Growth 18(3): 285-318.

Cerra, Valerie \& Sweta Chaman Saxena (2008) Growth dynamics: The myth of economic recovery. The American Economic Review 98(1): 439-457.

Chen, Siyan; Norman V Loayza \& Marta Reynal-Querol (2008) The aftermath of civil war. World Bank Economic Review 22(1): 63-85.

Colletta, Nat J \& Michelle L Cullen (2000) Violent conflict and the transformation of social capital : lessons from Cambodia, Rwanda, Guatemala, and Somalia. Washington, DC: World Bank.

Collier, Paul; V L Elliott, Håvard Hegre, Anke Hoeffler, Marta Reynal-Querol \& Nicholas Sambanis (2003) Breaking the conflict trap: civil war and development policy. Washington DC: World Bank and Oxford University Press.

Collier, Paul \& Anke Hoeffler (2004) Greed and grievance in civil war. Oxford Economic Papers 56(4): 563-595.

Collier, Paul; V L Elliott, Håvard Hegre, Anke Hoeffler, Marta Reynal-Querol, Jean-Philippe Peltier \& Nicholas Sambanis (2006) Breaking the conflict trap: Civil war and development policy. Economic Development and Cultural Change 54(4): 988-991.

Cox, James C (2004) How to identify trust and reciprocity. Games and Economic Behavior 46(2): 260-281.

Del Castillo, Graciana (2008) Rebuilding War-Torn States: The Challenge of Post-Conflict Economic Reconstruction: The Challenge of Post-Conflict Economic Reconstruction. Oxford: Oxford University Press.

De Leeuw, Edith D (2005) To mix or not to mix data collection modes in surveys. Journal of Official Statistics 21(2): 233-255.

De Luca, Giacomo \& Marijke Verpoorten (2015) Civil war, social capital and resilience in Uganda. Oxford Economic Papers 67(3): 661-686.

Deng, Luka Biong (2010) Social capital and civil war: The Dinka communities in Sudan's civil war. African Affairs 109(435): 231-250.

Derluyn, Ilse; Eric Broekaert, Gilberte Schuyten \& Els De Temmerman (2004) Post-traumatic stress in former Ugandan child soldiers. The Lancet 363(9412): 861-863.

Doyle, Michael \& Nicholas Sambanis (2006) Making War and Building Peace: The United Nations since the 1990's. Princeton: Princeton University Press.

Engel, Christoph (2011) Dictator games: A meta study. Experimental Economics 14(4): 583-610.

Fehr, Ernst \& Klaus M Schmidt (1999) A Theory of fairness, competition, and cooperation. The Quarterly Journal of Economics 114(3): 817-868.

Fischbacher, Urs \& Franziska Föllmi-Heusi (2013) Lies in disguise - An experimental Study on Cheating. Journal of the European Economic Association, 11(3): 525-547.

Frohlich, Norman (2004) Modeling other-regarding preferences and an experimental test. Public Choice 119(1): 91-117.

Gilligan, Michael J; Benjamin J Pasquale \& Cyrus Samii (2014) Civil war and social cohesion: Labin-the-field evidence from Nepal. American Journal of Political Science 58(3): 604-619.

IDMC (2010) UGANDA: Difficulties continue for returnees and remaining IDPs as development phase begins - A profile of the internal displacement situation. Geneva: Internal Displacement Monitoring Centre (http://www.internaldisplacement.org/assets/library/Africa/Uganda/pdf/Uganda-December-2010.pdf).

Iversen, Vegard; Cecile Jackson, Bereket Kebede, Alistair Munro \& Arjan Verschoor (2011) Do spouses realise cooperative gains? Experimental evidence from rural Uganda. World Development 39(4): 569-578. 
Jackson, Cecile (2013) Cooperative conflicts and gender relations: Experimental evidence from southeast Uganda. Feminist Economics 19(4): 24-47.

Joireman, Sandra F; Adam Sawyer \& Juliana Wilhoit (2012) A different way home: Resettlement patterns in Northern Uganda. Political Geography 31(4): 197-204.

Kahneman, Daniel; Jack L Knetsch \& Richard H Thaler (1986) Fairness and assumptions of economics. Journal of Business 59(4): 285-300.

Kaminska, Olena \& Tom Foulsham (2016) Eye-tracking social desirability bias. BMS: Bulletin of Sociologial Methodology 130(1): 73-89

Kebede, Bereket; Marcela Tarazona, Alistair Munro \& Arjan Verschoor (2014) Intra-household Efficiency: An Experimental Study from Ethiopia. Journal of African Economies 23(1): 105-150.

Knight, Andy W (2010) Linking DDR and SSR in post-conflict peace-building in Africa: An overview. African Journal of Political Science and International Relations 4(1): 29-54.

Moshagen, Morten; Benjamin E Hilbig, Edgar Erdfelder \& Annie Moritz (2013) An experimental validation method for questioning techniques that assess sensitive issues. Experimental Psycology 61(1): 48-54.

Ledyard, John O (1995) Public goods: A survey of experimental research. In: John Kagel \& Alvin Roth (eds) Handbook of Experimental Economics. Princeton, New Jersey: Princeton University Press, 111-193.

Leider, Stephen; Markus M Möbius, Tanya Rosenblat \& Quoc-Anh Do (2009) Directed altruism and enforced reciprocity in social networks. Quarterly Journal of Economics 124(4): 1815-1851.

Levitt, Steven D \& John A List (2007) What do laboratory experiments measuring social preferences reveal about the real world? The Journal of Economic Perspectives 21(2): 153-174.

Ligon, Ethan \& Laura Schechter (2012) Motives for sharing in social networks. Journal of Development Economics 99(1): 13-26.

Muggah, Robert (2005) No magic bullet: A critical perspective on disarmament, demobilization and reintegration (DDR) and weapons reduction in post-conflict contexts. The Round Table 94(379): 239-252.

Munro, Alistair; Bereket Kebede, Marcela Tarazona-Gomez \& Arjan Verschoor (2014) Autonomy and efficiency. An experiment on household decisions in two regions of India. Journal of the Japanese and International Economies 33(2014): 114-133.

Murdoch, James C \& Todd Sandler (2002) Economic growth, civil wars and spatial spillovers. Journal of Conflict Resolution 46(1): 91-110.

Murdoch, James C \& Todd Sandler (2004) Civil wars and economic growth: Spatial dispersion. American Journal of Political Science 48(1): 138-151.

Özerdem, Alpaslan (2012) A re-conceptualisation of ex-combatant reintegration: 'social reintegration' approach. Conflict, Security \& Development 12(1): 51-73.

Paris, Roland (2004) At War's End: Building Peace after Civil Conflict. Cambridge: Cambridge University Press.

Pham, Phuong N; Patrick Vinck \& Eric Stover (2009) Returning home: Forced conscription, reintegration, and mental health status of former abductees of the Lord's Resistance Army in northern Uganda. BMC psychiatry 9(23): 1-14.

Pham, Phuong \& Patrick Vinck (2010) Transitioning to peace: A population based survey on attitudes about social reconstruction and justice in northern Uganda. Human Rights Center: University of Berkeley (https://www.law.berkeley.edu/files/HRC/Publications_Transitioning-to-Peace_122010.pdf).

Rodrik, Dani (1999) Where did all the growth go? External shocks, social conflict, and growth collapses. Journal of Economic Growth 4(4): 385-412.

Rohner, Dominic; Mathias Thoenig \& Fabrizio Zilibotti (2011) Seeds of distrust: Conflict in Uganda. Center for Institutions, Policy and Culture in the Development Process Working Paper Series 417: $1-48$. 
Spear, Joanna (2006) From political economies of war to political economies of peace: The contribution of DDR after wars of predation. Contemporary Security Policy 27(01): 168-189.

Sugden, Robert (1984) Reciprocity: The supply of public goods through voluntary contributions. Economic Journal 94(376): 772-787.

Tajfel, Henri \& John C Turner (1979) An integrative theory of intergroup conflict. In: William G Austin \& Stephen Worchel (eds) The Social Psychology of Intergroup Relations. Monterey, CA: Brooks-Cole, 33-47.

Tajfel, Henri \& John C Turner (1986) The social identity theory of intergroup behaviour. In: Stephen Worchel \& William G Austin (eds) Psychology of Intergroup Relations. Chicago, IL: Nelson-Hall, 7-24.

Thapa, Deepak (2003) Understanding the Maoist Movement in Nepal. Kathmandu: Martin Chautari.

Tourangeau, Roger \& Ting Yan (2007). Sensitive questions in surveys. Psychological Bulletin 133(5): 859-883.

UNDP (2001) Role of UNDP in crisis and post-conflict situations. New York: United Nations Development Programme.

UNHCR (2012) Briefing Notes, 6 January 2012: UNHCR closes chapter on Uganda's internally displaced people http://www.unhcr.org/4f06e2a79.html

Van de Mortel, Thea F (2008) Faking it: Social desirability response bias in self-report research. Australian Journal of Advanced Nursing 25(4): 40.

Verschoor, Arjan; Ben D’Exelle \& Borja Perez-Viana (2016) Lab and life: Does risky choice behaviour observed in experiments reflect that in the teal world? Journal of Economic Behavior and Organization 128(August): 134-148.

Werner, Güth; Rolf Schmittberger \& Bernd Schwarze (1982) An experimental analysis of ultimatum bargaining. Journal of Economic Behavior and Organization 3(4): 367-388.

Whitt, Sam \& Rick K Wilson (2007) The dictator game, fairness and ethnicity in postwar Bosnia. American Journal of Political Science 51(3): 655-668.

PLEASE INSERT YOUR BIO SKETCHES HERE - Please refer to section 15 or our Notes for Authors for style/format: http://file.prio.no/journals/JPR/JPR-Notes-forAuthors.pdf 